\title{
Smoking and asthma: dangerous liaisons
}

\author{
Riccardo Polosa* and Neil C. Thomson"
}

\begin{abstract}
Cigarette smoking and asthma interact to induce important adverse effects on clinical, prognostic and therapeutic outcomes. This review examines recent evidence on the harmful effects of smoking in asthma, possible underlying inflammatory mechanisms for this altered response, management options for these patients and potential future therapeutic directions. Active smokers, particularly females, are at risk of developing asthma. Prevalence rates for smoking in asthma are relatively close to those found in the general population. Smokers with asthma experience worse asthma control than nonsmokers with asthma. Mechanisms for the adverse effects of smoking in asthma include altered airway inflammation and corticosteroid insensitivity. Quitting smoking can improve symptoms and lung function, but the low rates of smoking cessation highlights the need for improved strategies for managing these patients. Clinical trials assessing new therapies for asthma need to enrol smokers to identify treatments that are effective in the asthma smoking phenotype.
\end{abstract}

KEYWORDS: Asthma, smoking, smoking cessation obacco smoking is the leading cause of preventable premature mortality in the world and quitting is known to substantially reduce the risk of serious diseases such as lung cancer, cardiovascular disease, strokes, chronic lung disease and other cancers [1]. In spite of chronic respiratory symptoms, it is remarkable that asthma sufferers commence and continue smoking with prevalence rates relatively close to those found in the general population [2-5]. This paradox may be partially explained by the highly addictive nature of tobacco smoking and the remitting characteristic of asthma, particularly in its mildto-moderate forms.

An impressive amount of clinical, functional, pathologic and management data has been collected in chronic obstructive pulmonary disease (COPD), the archetype of smoking-induced airway disease, but until recently, relatively little was known about the relationship between active smoking and asthma owing to the exclusion of smokers from mechanistic studies and clinical trials reflecting a concern over recruiting subjects with COPD. Recognition of an "asthma smoking phenotype" has important implications for research designed to understand mechanisms of disease and management of this sub-group of asthma. The expanding appreciation that smoking aggravates asthma suggests that quitting may confer additional clinical benefit in individuals with asthma who smoke. Moreover, smoking may predict successful responses to some anti-asthma treatment, but not others, and improved phenotyping of patients with asthma who smoke will become increasingly important for the design of future clinical trials and for drug development. This review examines the evidence for adverse effects of smoking in the context of asthma, possible underlying inflammatory mechanisms for this altered response, management options for these patients and potential future therapeutic directions. Data for this review were identified by searches of Medline, Current Contents, PubMed, clinicaltrials.gov and references from relevant articles using the search terms "asthma", "smokers", "smoking" and "smoking cessation". Abstracts and reports from meetings were included only when they related directly to previously published work. Only articles published in English between 1980 and 2012 were included.

\section{SMOKING AS A RISK FACTOR FOR THE DEVELOPMENT OF ASTHMA}

Epidemiological evidence for the association between active cigarette smoking and asthma lacks some consistency. Population studies are hampered by cross-sectional and case-control study design, the use of poor measures of tobacco smoke exposure and, due to their reliance on selfreport measures or questionnaires, the potential for inaccuracies in the diagnosis of asthma as a result of recall bias. Nevertheless, the overall patterns of results indicate a higher prevalence
AFFILIATIONS

*Institute of Internal Medicine and Clinical Immunology, AOU

"Policlinico-Vittorio Emanuele", Università di Catania, Catania, Italy. \# Institute of Infection, Immunity and Inflammation, University of Glasgow, Glasgow, UK.

CORRESPONDENCE

R. Polosa

Istituto di Medicina Interna e Immunologia Clinica, Policlinico Universitario

University of Catania

95100

Catania

Italy

E-mail:polosa@unict.it

Received:

May 082012

Accepted after revision:

July 262012

First published online:

Aug 162012 
of asthma particularly among female smokers compared to female nonsmokers (table 1) [6-9]. For example, the Canadian National Population Health Survey [7] reported that female smokers had a $70 \%$ higher prevalence rate of asthma compared to nonsmokers, and the interaction between smoking and sex was particularly evident among females aged $<25$ yrs (OR 2.18) and among heavier as compared to lighter smokers or nonsmokers. The majority of studies that have investigated a temporal association between smoking and onset of asthma support the suggestion that smoking places an individual at a significantly increased risk of developing asthma (table 1) [1014]. In an attempt to address whether smoking is a causal or a proxy risk factor, a large cohort of clinic-referred non-asthmatic adult subjects with established allergic rhinitis was investigated to determine the importance of active cigarette smoking as an additional risk factor for incident asthma at 10-yrs follow-up [15]. Smoking was strongly predictive of the development of new onset asthma in allergic adults. In particular, the intensity of smoking appeared to be clearly associated given that there was a dose response in the effect of smoking exposure with the risk of new onset asthma.

A series of systematic reviews and epidemiological surveys provide compelling evidence of a causal relationship between parental smoking and the development of asthma in children [44-47]. A recent systematic review and meta-analysis of 76 studies examining the effect of exposure to pre- or post-natal passive smoke reported a $21-85 \%$ increased risk of incident asthma [46]. The strongest effect from prenatal maternal smoking on asthma in children aged $<2$ yrs had an OR of 1.85 (95\% CI 1.32.5) [3]. In adolescents and adults, exposure to passive smoke is also associated with the development of asthma [45].
Interestingly, childhood exposure to passive smoke has been shown to be associated with an increased risk of developing asthma as an adult with an OR of 1.9 (95\% CI 1.6-3.2) [48].

\section{CLINICAL OUTCOMES IN SMOKERS WITH ASTHMA}

Increased morbidity and mortality have been reported in asthmatic individuals who smoke (table 1) [16]. Compared to asthmatic nonsmokers, this group of patients is at risk of developing more severe symptoms and worse asthma-specific quality of life with a huge impact on healthcare resources due to unscheduled doctor visits and frequent hospital admissions [17-20]. Moreover, cigarette smoking in asthma is associated with higher frequency of exacerbations [21], increased numbers of life threatening asthma attacks [22], and asthma mortality is greater among heavy smokers with asthma compared to asthmatics who do not smoke [23]. During pregnancy, exacerbations are more common and more severe in current smokers than never-smokers with asthma [49] and fetal growth abnormalities are more common [50].

In line with these observations, asthma severity is greater in asthmatics who smoke (table 1) [17-20]. Using the Global Initiative for Asthma severity classification [51], data from a well-characterised clinic cohort of allergic subjects at high risk for incident asthma followed up for 10 yrs shows that smoking status and smoking duration are markedly related in a dose-dependent fashion to the level of asthma severity [24]. The strongest association with disease severity was observed in those who smoked $>20$ pack-yrs. The demonstration of a strong association between active cigarette smoking and severity of asthma and the clear-cut dose-response relationship is in support of causality.

It is now recognised, however, that classification by disease severity simply suggests a static feature, which is clearly not the

TABLE 1 Summary of adverse effects of active cigarette smoking and asthma

Adverse effects of active smoking and asthma

Increased prevalence of asthma

Incident asthma

Increased asthma morbidity and mortality

Greater asthma severity

Uncontrolled asthma

Accelerated decline in lung function

Persistent airflow obstruction

Corticosteroid insensitivity
Details of adverse effects

Higher prevalence of asthma particularly among female smokers compared to female nonsmokers; the interaction between smoking and sex is particularly evident among heavier smokers compared to lighter smokers or nonsmokers [6-14]

Smoking is highly predictive of the development of new onset asthma in allergic adults with a clear dose-response effect of smoking exposure [15]

Asthmatic smokers are at risk of developing more severe symptoms, higher frequency of exacerbations, and worse asthma-specific quality of life [16-21]; cigarette smoking in asthma is also associated with increased numbers of life threatening asthma attacks and greater asthma mortality $[22,23]$

Smoking status and smoking duration are strongly related in a dose-dependent fashion to the level of asthma severity [24]

The strongest association with disease severity was observed in those who smoked $>20$ pack-yrs A relationship between smoking and poor asthma control has been reported in population-based surveys [25-29] and in controlled studies [24, 25]

Smoking status and smoking duration are also related to poor asthma control in a dose-dependent fashion [24]

The rate of decline in lung function is accelerated in smokers with asthma compared with nonsmokers with asthma [30-34], although there are also a few negative studies [36, 37]

A proportion of smokers with asthma develop persistent airflow obstruction [31, 32] Asthma patients who smoke appear to be less sensitive to the beneficial effects of corticosteroids with regard to respiratory symptoms and lung function, irrespective of the route of administration of treatment [37-43] 
case in everyday clinical asthma where the level of severity varies in relation to the amount of anti-asthma medication taken. These considerations have promoted the more clinically informative concept of asthma control $[52,53]$. Several studies have demonstrated a strong relationship between cigarette smoking and poor asthma control in population-based surveys from Switzerland [26], the UK [25, 27], France [28] and the USA (table 1) [29]. In a well-characterised cohort of allergic individuals at risk for new onset asthma, smoking status and smoking duration were also related to poor asthma control in a dosedependent fashion [24].

As with active cigarette smoking, exposure to passive smoke has a number of adverse effects on asthma control and severity in children and adults. In children with asthma, passive smoke exposure results in increased asthma symptom scores, exacerbation frequency, use of reliever medication, hospitalisation rates and number of life-threatening attacks [45]. Adults with asthma who are exposed to passive smoke have poor symptom control, worse quality of life, lower lung function and greater healthcare utilisation $[45,54]$. A study from Scotland, UK, looked at the effect of the ban of smoking cessation in public places on airway inflammation and quality of life in bar workers. Asthmatic bar workers had less airway inflammation with a reduction in exhaled nitric oxide from 34.3 parts per billion (ppb) to $27.4 \mathrm{ppb} 4$ weeks after the ban and the asthma quality-of-life scores improved by 7.3 points [55].

\section{EFFECTS OF SMOKING ON LUNG FUNCTION}

Smoking a cigarette can cause acute bronchoconstriction particularly in asthmatic smokers with reduced baseline lung function [56, 57]. The effect of smoking on the progressive decline in lung function in COPD is well established [58] and more recent studies have shown that accelerated decline in lung function over time is also present in asthmatic individuals $[30,31]$. In most longitudinal studies, the rate of decline in lung function is accelerated in smokers with asthma compared with nonsmokers with asthma (table 1) [30-34]. For example, JAMES et al. [34] demonstrated an additive effect of smoking and asthma upon decline in forced expiratory volume in $1 \mathrm{~s}$ (FEV1), wherein the most rapid decline in lung function for males and females was observed in the smoking asthmatic compared to healthy smokers or asthmatic nonsmokers. However, there are also a few negative studies [31, 36], but these included a relatively low number of smokers with asthma and may have had insufficient power to detect an effect of tobacco exposure on lung function decline. Accelerated loss of lung function in adulthood as well as genetic and environmental risk factors (other than smoking), and sub-maximal lung growth in childhood may also contribute to the development of persistent airflow obstruction in smokers with asthma [31, 32]. Individuals with a history of severe asthma in childhood who go on to smoke as adults may be particularly at risk. It is worth noting that lung function changes in asthma can improve with weeks of smoking cessation [59].

\section{SMOKING AND REDUCED CORTICOSTEROID SENSITIVITY}

Asthma patients who smoke are less sensitive to the beneficial effects of short-to-medium term treatment with inhaled corticosteroids (ICS) or oral corticosteroids with regard to improvements in respiratory symptoms, lung function and exacerbation rates compared to asthma patients who do not smoke (table 1) [37-43]. Although increased ICS dosage may partially reverse unresponsiveness [40], evidence from clinical trials indicates that reduced sensitivity to corticosteroids persists irrespective of the route of administration of treatment or the formulation of ICS [16]. There is limited data on the effects of long-term treatment with ICS on the rate of decline in lung function in smokers with asthma. In a 23-yr follow-up of adult patients with moderate-tosevere asthma, ICS did not reduce the annual decline in FEV1 in individuals who smoked [60] except for a subgroup of males who had a light smoking history. In a further observational study the rate of decline in FEV1 in smokers with asthma was reduced from $58 \mathrm{~mL}$ per year in subjects not receiving ICS to $31 \mathrm{~mL}$ per year in those receiving treatment with ICS [61]. In support of these findings, the benefits of therapy with inhaled budesonide on preventing lung function decline are similar in light smokers and nonsmokers with mild persistent asthma [62].

\section{MECHANISMS FOR THE ADVERSE CONSEQUENCES OF SMOKING IN ASTHMA}

The mechanisms accounting for the adverse consequences of smoking in asthma, including poor symptom control, accelerated decline in lung function and reduced sensitivity to corticosteroids are poorly understood, but are likely to be due to differences in airway inflammation in smokers compared to nonsmokers with asthma (fig. 1).

There is now accumulating evidence that both tobacco smoke and asthmatic inflammation may induce important changes in the asthma endotype with a predominance of activated macrophages and neutrophils as in early COPD [63, 64]. Thus, it may be speculated that persistent exposure to cigarette smoke drives additive or synergistic inflammatory and remodelling responses in the asthmatic airways thus explaining the reported accelerated decline in lung function and increased severity of airflow obstruction. Neutrophils may also contribute to mucous hypersecretion through release of neutrophil elastase and via induction of mucin genes in bronchial epithelial goblet cells and submucosal glands. Chronic mucus hypersecretion may be an additional risk factor for the accelerated decline in FEV1. Importantly, neutrophil numbers in airways is known to correlate to rate of decline in lung function [65]. The majority of smokers with asthma have non-eosinophilic endotype in the asthmatic airways, but increased numbers of mast cells have been also identified in smokers with asthma compared to nonsmokers [66]. The relative inflammatory contribution due to cigarette smoking and asthma is likely to vary between individuals due to differences in the duration and intensity of exposure to cigarette smoke, as well as to the duration and severity of asthma.

Modulation of inflammation, repair, and pathologic repair (remodelling) is also dependent upon delicate balances of matrix metalloproteinases (MMPs) and their intrinsic inhibitors, tissue inhibitors of metalloproteinases [67]. Sputum MMP-12 concentrations are elevated in smokers with asthma compared to nonsmokers with asthma and the levels are inversely associated with lung function and positively related 


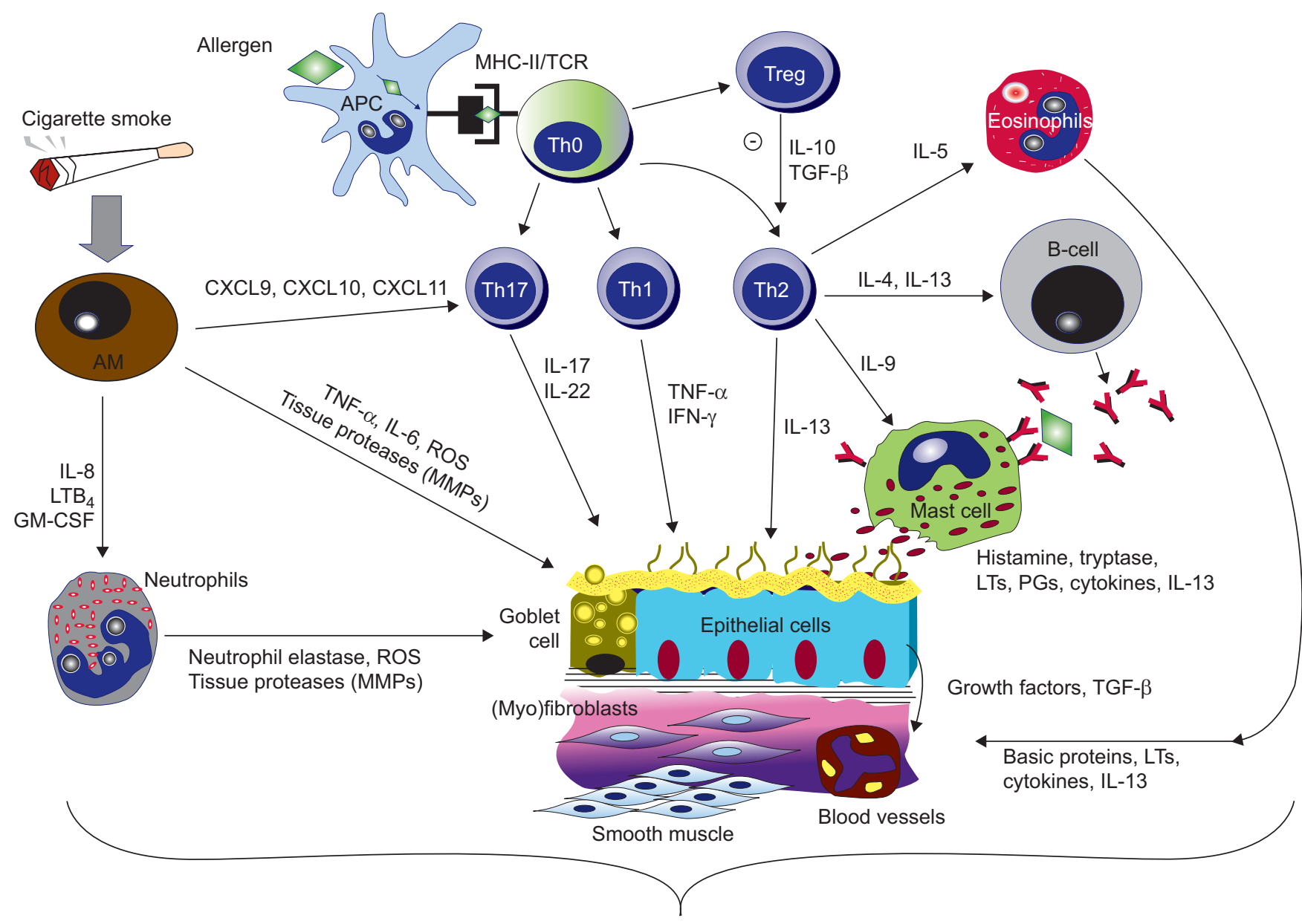

Asthma smoking phenotype

FIGURE 1. Underlying inflammatory mechanisms for the mixed asthma-smoking phenotype. In allergic asthma, initial exposure(s) of professional antigen-presenting cells (APCs) to allergen mainly leads to the activation of allergen-specific T-helper (Th)2 cells and immunoglobulin (Ig)E synthesis. Subsequent exposures to allergen cause inflammatory-cell recruitment (e.g. eosinophils) and activation (e.g. mast cells) and mediator release; these inflammatory events are responsible for the characteristic early and late responses of the airways. There is now evidence that Th1-cell responses might also be responsible for some of the pathogenic features in patients suffering from chronic forms of atopy, including epithelial apoptosis and smooth-muscle cell activation. Regulatory T-cells (Treg) are another important subset of CD4+ T-cells with implications for the suppression of Th2-cell responses in humans involving the inhibitory cytokines interleukin (IL)-10 and transforming growth factor (TGF)- $\beta$. The newly identified CD4+ T-cell subset, Th17 cells, seems to be specifically associated with the neutrophilic inflammatory events that occur during disease exacerbation and in tissue remodelling. Cigarette smoke combined with asthmatic inflammation may induce important changes in the asthma endotype with a predominance of activated macrophages (AM) and neutrophils in sputum, airways and lung parenchyma as in early chronic obstructive pulmonary disease. When activated by cigarette smoke, AMs will produce a myriad of pro-inflammatory molecules, reactive oxygen species (ROS), tissue proteases (e.g. matrix metalloproteinase (MMPs)), and chemokines involved in the mobilisation and prolonged survival of neutrophils in the lung tissue (e.g. IL-8). Interestingly, AMs in the smokers appear to produce less IL-10, which leads to less Th2-cells development and reduced B-cell number and lower levels of IL-4 and IL-5. This will produce fewer and less active eosinophils and lower production of IgE in smoking asthmatics. Activated AMs are involved in the direct stimulation of Th1 and Th17 cells that in turn promote bronchial epithelial cells and goblet cell activation to increase inflammatory responses, mucous production and tissue remodelling. Cigarette smoke might also directly activate bronchial epithelial cells to release further pro-inflammatory cytokines, chemokines, growth factors and TGF- $\beta$, which are known to modulate smooth muscle cell and fibroblast proliferation with subsequent progression to fibrosis and extracellular matrix deposition. In smoking, asthma-increased levels of thymic stromal lymphopoietin may further stimulate mast cells to release remodelling mediators, such as IL-13, independently of Th2 cells. Increased MCs, together with smoking-induced epithelial cell activation, may increase IL-8 production, contributing to further infiltration of neutrophils. Neutrophil infiltration is known to favour the progression of the inflammatory response and lung damage of the smoker because they are a rich source of inflammatory mediators including ROS, lipid mediators and tissue proteases (e.g. neutrophil elastase). The persistent exposure to cigarette smoke drives additive or synergistic inflammatory and remodelling responses (e.g. chronic mucus hypersecretion) in the asthmatic airways thus explaining the reported accelerated decline in lung function and increased severity of airflow obstruction. $\mathrm{LTB}_{4}$ : leukotriene $\mathrm{B}_{4}$; GM-CSF: granulocyte-macrophage colony-stimulating factor; MHC: major histocompatibility complex; TCR: T-cell receptor; TNF- $\alpha$ : tumour necrosis factor- $\alpha$; IFN: interferon- $\gamma$; LTs: leukotrienes; PGs: prostaglandins.

to sputum neutrophil counts [68]. Of note, the admixture of proteolytic enzymes released in the course of allergic inflammation e.g. mast cell tryptase, can convert the inactive "pro" form of MMP-12 or MMP-9 to active forms, further enhancing the pro-inflammatory signal of the MMP cocktail. It is likely that both smoking and allergic asthma provide pro-inflammatory stimuli at multiple levels, including MMP dysregulation and, thus, can be additive in lung damage. 
In allergic individuals, persistent exposure to cigarette smoke and allergen in combination may have complex effects on adaptive and innate immune responses resulting in distinct asthma inflammatory endotypes. Human and animal studies have shown that the polyaromatic hydrocarbons (present in the particulate phase of cigarette smoke and diesel fumes), have the ability to induce allergic immune responses and enhance $\mathrm{T}$ helper (Th)2-type inflammation [69, 70]. Thus, progression to asthma in sensitised individuals it is likely to be expected in those who smoke regularly. Irritant substances in cigarette smoke may also have the ability to induce airway hyperresponsiveness and chronic inflammation in the airways by innate immune responses [71, 72], thus contributing to the enhanced risk of developing asthma.

Persistent exposure to cigarette smoke not only enhances allergic Th2-driven inflammation [73], but also Th1-mediated inflammatory responses $[63,64]$. Given that a mixed Th1/Th2 inflammatory response is a key event in the process of developing a more severe asthma phenotype [74], development of a more severe disease may be anticipated in those allergic individuals who smoke regularly. Neutrophils are not normally responsive to corticosteroids, and one might speculate that cigarette smoking, by inducing a neutrophilpredominant endotype in the asthmatic airways [63,64], sets the stage for unresponsiveness to asthma treatment. The paucigranular inflammatory phenotype found in some smokers with asthma would also be insensitive to corticosteroids [37]. Other possible mechanisms explaining corticosteroid unresponsiveness in smoking asthmatics may be related to oxidative stress. Cigarette smoke may induce oxidative stress which not only activates the nuclear factor- $\kappa \mathrm{B}$ pathway but also alters the histone deacetylase (HDAC)/histone acetyltransferases balance via post-translational modification of HDAC2 [75, 76]. Another possible mechanism explaining the observed corticosteroid unresponsiveness might be a reduced glucocorticoid receptor $\alpha$ : $\beta$ ratio, which is observed in healthy smokers as well as in asthmatic smokers [77].

Besides the putative cellular and molecular mechanisms to try and explain the reduced responsiveness to corticosteroids and the tendency to have uncontrolled disease, it is also important to consider the role of non-adherence [78] and misdiagnosis with COPD. Research suggests that up to one-third of smokers aged $>40$ yrs with a diagnosis of asthma may in fact have COPD [79] or overlap airway disease. In addition, exposure to cigarette smoke can increase ICS particle size and so decrease its deposition within the airways, which may reduce sensitivity to corticosteroids [80].

Respiratory infections are major triggers of asthma exacerbation, and this may have direct implications for poor asthma control in smoking asthmatics. Many physicians feel that asthmatics who smoke have a greater susceptibility to respiratory infections, although there is limited specific research in this area. VERNASKE et al. [81] evaluated baseline characteristics of 101 patients admitted to hospital with an asthma exacerbation. Rhinovirus detection was strongly associated with hospitalisation for asthma, and after adjustment for baseline asthma severity, rhinovirus-positive patients were more likely to be current smokers. PATEL et al. [21] reported that cigarette smoking in asthma is associated with higher frequency of exacerbations. In addition, findings from the European Community Respiratory Health Survey appear to suggest that acute bacterial asthma exacerbations may be linked to parental smoking [82].

\section{ASTHMA AND SMOKING CESSATION}

Apart from the obvious consideration that quitting smoking has an overall health advantage, abstinence from smoking may also be beneficial for several specific aspects of asthma control. In spite of the reported deleterious effects of smoking on asthma symptoms, lung function and corticosteroid responsiveness, only a few studies have examined the role of smoking cessation on asthma outcomes. Overall, these studies show improvements in symptoms and lung function in those asthmatics who quit smoking successfully (table 2).

The pioneering study by FENNERTY et al. [84], investigated the effects of smoking cessation in 14 asthmatic patients at $24 \mathrm{~h}$ and after 7 days of abstinence. No change in mean symptom scores or bronchodilator usage was observed post-cessation, but there

TABLE 2 Summary of studies examining the effect of smoking cessation on asthma outcomes
First author [ref.]
Participants
Findings

TONNESEN [83]

220 asthmatics undergoing a smoking cessation programme with NRT

At 4 months, 27 were abstainers, 33 reducers and 50 relapsers or continuing smokers

PicCILLo [72]

Chaudhuri [59]
57 smokers with seasonal allergic rhinitis \pm asthma undergoing a smoking cessation programme with NRT \pm bupropion At 12 months, 16 of the participants had quit smoking 32 asthmatic smokers given the option to quit or continue smoking 11 opted to continue smoking, whereas 10 out of 21 managed to quit smoking for up to 6 weeks
Improvements in the asthma-specific quality-of-life score, and reductions in self-reported day and night use of rescue $\beta_{2}$-agonists, doses of ICS, daytime asthma symptoms and AHR were reported in the abstainers

For reducers, smaller improvements occurred for night use of rescue $\beta_{2}$-agonists, doses of ICS and AHR

A significant improvement in AHR to direct and indirect bronchoprovocation was observed after cessation in the quitters but not in the smoking cessation relapsers

After smoking cessation, quitters achieved considerable improvement in lung function and a fall in sputum neutrophil count compared with subjects who continued to smoke

NRT: nicotine replacement therapy; AHR: airway hyperresponsiveness; ICS: inhaled corticosteroids. 
was a significant increase in peak expiratory flow (PEF). Although there was no significant change in airway hyperresponsiveness to histamine after $24 \mathrm{~h}$, there was a significant improvement after 7 days. Interestingly, two participants reported a worsening of their asthma symptoms upon quitting. Those who relapsed reported they did so because of withdrawal effects and not because of worsening asthma symptoms. More recently, in a prospective study on three groups of asthma patients of smoking reduction, complete smoking cessation or continuation of smoking [83], asthmatic smokers who quit had significant improvement in asthma-related quality of life and reduction in nocturnal and daytime rescue $\beta_{2}$-agonist use, ICS use, daytime asthma symptoms and airway hyperreactivity. Of note, smaller improvements occurred in smoking reducers suggesting an apparent dose-response effect. These findings agree with a large longitudinal study demonstrating improvement in airway hyperresponsiveness 1 yr after smoking cessation in those smokers for whom an objective proof of cessation was obtained [72]. Finally, a study of 32 smokers with asthma showed clinically important improvements in mean FEV1 of $450 \mathrm{~mL}$ in 10 out of 21 participants who managed to quit smoking for up to 6 weeks compared to those who continued smoking [59]. Moreover, asthma control improved, corticosteroid responsiveness in smoking asthmatics was restored and there was a decrease in sputum neutrophils after 6 weeks of smoking cessation.

The above findings highlight the importance of smoking cessation in improving clinical and pathological outcomes of asthma. Physicians have the responsibility to alert their patients with asthma about the additional risks of smoking and to engage in smoking cessation interventions. Unfortunately, the powerful addictive qualities of tobacco smoking create a huge hurdle, even for those with a strong desire to quit and multiple attempts and long-term treatment may be required to achieve enduring abstinence. However, only modest cessation rates have been reported in adult asthma and some studies have reported that asthmatic smokers do not believe that smoking could be a serious problem for their asthma. Furthermore, the decision to quit smoking depends strongly on the beliefs and habits of the patients. Although in a recent survey, $51 \%$ of smokers with asthma reported that they would be willing to attend smoking cessation advice sessions [27], only modest cessation rates are reported in asthma [85]. Surprisingly, in a large survey in South Australia it was found that $>40 \%$ of smoking asthmatics did not believe that smoking could be a serious problem for their asthma [86].

In view of the powerful interaction between physical and psychological components associated with tobacco dependence, current evidence-based recommendations indicate that smoking cessation programmes should combine counselling (mainly problem solving/skills training, and social support) and medications for nicotine addiction for best results [87]. Presently, first-line medications for smoking cessation therapy include nicotine replacement therapy, bupropion and varenicline. Moreover, improved understanding of the mechanisms involved in nicotine dependence has recently been translated into new medications for improved nicotine abstinence [88]. Several factors are known to indicate whether a smoker is more likely to quit or not and this knowledge may increase quit rates.
Although not specifically studied in asthmatic smokers, these are known to include late initiation of cigarette smoking, longer duration of previous quit attempts, lack of depression, low-tomoderate nicotine dependence, absence of alcohol problems, sustained level of motivation, being married and/or not having any other smokers in the household [89]. In practice, symptoms of asthma (primarily cough) can develop or worsen after smoking cessation [90]. Thus, the asthmatic smoker who wants to quit should be advised that his/her symptoms of asthma may increase within the first couple of weeks after smoking cessation. Smokers' in this category will benefit from a temporary increase in anti-asthma drugs. Moreover, given that children with asthma are extremely vulnerable to second-hand smoke, their parents and other family members who smoke should be offered treatment for smoking cessation [91]. "Offer help to quit tobacco use" in people addicted to nicotine is one of the six proven policies identified by the World Health Organization Framework Convention on Tobacco Control to expand the fight against the tobacco epidemic [92], but to be effective this approach requires integration with a comprehensive tobacco control strategy [93]. Further approaches to smoking cessation are under investigation in specific groups including smoking parents of children with asthma (www. clinicaltrials.gov; NCT00862368), ethnically diverse population of inner-city schoolchildren with asthma (www.clinicaltrials. gov; NCT01175369), adolescent with asthma (www.clinicaltrials.gov; NCT01170676), patients attending emergency departments with asthma (www.clinicaltrials.gov; NCT01079000) and mothers during and after pregnancy (www.clinicaltrials.gov; NCT00499915).

\section{CURRENT PHARMACOLOGICAL TREATMENTS}

Beyond smoking cessation, asthma guideline recommendations on drug treatment of asthmatics who smoke do not, in general, differ from nonsmokers with asthma (table 3) [51]. However, this view could be challenged given that most of the recommendations on drug treatment are based on clinical studies in which patients are carefully selected to exclude current smokers or former heavy smokers. The lack of information on the best approach to manage smokers is of significant concern, given the high prevalence rates of active smoking in asthma and the poor levels of asthma control in this specific subgroup [94].

In addition to short-acting $\beta_{2}$-agonist therapy, should symptomatic smokers at step 2 be treated by the addition of a low-tomedium dose ICS? Despite smokers with asthma having reduced sensitivity to corticosteroids, it seems appropriate that these patients receive ICS for several reasons. First, long-term ICS treatment may reduce the decline in lung function in some smokers with asthma [60-62]. Secondly, not all smokers with asthma are insensitive to ICS, perhaps because of difference in smoking history and/or airway inflammation. Nevertheless, the majority of smokers with asthma are likely to continue to be symptomatic despite ICS and in these patients a step-up in therapy will be required. In several recent studies the addition of a long-acting $\beta_{2}$-agonist has been shown to benefit smokers with asthma $[31,95,98]$ and this is likely to be a preferable option to that of increasing the dose of ICS [40], because of the potential of adverse effects from the latter option. In smokers 
TABLE 3 Possible treatment options for asthmatic smokers beyond smoking cessation

Therapeutic options

Step 1

Step 2

Steps 3 and 4

\section{Short-acting $\beta_{2}$-agonist therapy as needed \\ Low dose ICS}

Despite most smokers with asthma having reduced sensitivity to corticosteroids, it seems appropriate that asthmatics who smoke receive ICS because not all smokers are insensitive to ICS and steroid treatment may reduce the rate of decline in lung function in smokers [60-62]

\section{Leukotriene receptor antagonists}

Leukotriene receptor antagonists may have preferential beneficial effect on PEF in smokers with mild asthma compared to nonsmokers with mild asthma [39]

The preliminary findings of a randomised, parallel-group 6-month study to evaluate the efficacy of oral montelukast, fluticasone propionate and placebo in 1019 patients with chronic asthma who smoke cigarettes reported that both interventions produced small improvements in the percentage of asthma-control days (primary outcome) compared to placebo (www.clinicaltrials.gov; NCT00284856)

Many smokers with asthma continue to be symptomatic despite low-dose ICS and in these patients a step-up in therapy will be required Additional therapies include one or more of the following options:

Long acting $\boldsymbol{\beta}_{2}$-agonist plus low-to-medium dose ICS

Combination of inhaled fluticasone and salmeterol produced significant improvements in airway hyperresponsiveness, airway calibre and annual exacerbation rate compared to doubling the dose of inhaled fluticasone [42, 95]

Similar benefits were reported with the combination of inhaled budesonide and formoterol [86]

High-dose ICS

Short-term treatment with high-dose ICS produces improvements in lung function in smokers with asthma [40], but long-term treatment with ICS may increase the risk of adverse effects

Leukotriene receptor antagonists

Benefit in smokers with asthma unknown

Low dose theophylline

The addition of low-dose sustained release theophylline restores ICS sensitivity as measured by lung function in smokers with asthma [96]

Tiotropium

Possible benefit particularly in smokers with asthma associated with persistent airflow obstruction [97]

The therapeutic options are based on the Global Initiative for Asthma guidelines steps [51]. ICS: inhaled corticosteroids; PEF: peak expiratory flow.

with mild-to-moderate asthma, the combination of inhaled fluticasone and salmeterol taken in a dose of $250 / 50 \mu \mathrm{g}$ twice daily produced significant improvements in airway hyperresponsiveness as well as in airway calibre compared to doubling the dose of inhaled fluticasone [95]. A post hoc analysis of the Gaining Optimal Asthma Control trial found that smokers with asthma had reduced exacerbation rates with combination therapy with inhaled fluticasone and salmeterol (0.20 per patient per year) compared to inhaled fluticasone alone $(0.35$ per patient per year) [42]. An open label study of asthmatic patients with a limited smoking history showed benefits from treatment with the combination of inhaled budesonide and formoterol administered as a maintenance and reliever therapy [98]. With regards to other options, the leukotriene receptor antagonist montelukast was found in a proof of concept clinical trial to increase morning PEF values in smokers with mild asthma, but not in nonsmokers with mild asthma, suggesting that there may be a greater benefit of leukotriene receptor antagonists in smokers [39]. The preliminary findings of a randomised, parallel-group 6-month study to evaluate the efficacy of oral montelukast, fluticasone propionate and placebo in 1,019 patients with chronic asthma who smoke cigarettes reported that both interventions produced small improvements in the percentage of asthma-control days (primary outcome) compared to placebo (www.clinicaltrials.gov; NCT00284856). The efficacy of adding anti-leukotriene drugs to combination therapy in smokers with asthma is not known. A recent 12-week study found that patients with COPD and concomitant asthma achieve improvements in lung function with the inhaled tiotropium, which suggests that inhaled tiotropium may be of benefit in smokers, particularly when associated with persistent airflow obstruction [97]. A further study is underway examining the efficacy of inhaled tiotropium compared with an inhaled long-acting $\beta_{2}$-agonist in smokers with asthma (www.clinicaltrials.gov; NCT00546234).

\section{FUTURE THERAPIES FOR SMOKERS WITH ASTHMA}

There is an unmet need for improved therapies to manage smokers with asthma who are unable to stop smoking, both by targeting smoking cessation as well as by the development of drugs that restore corticosteroid sensitivity and/or antagonise the effects of pro-inflammatory pathways and oxidative stress relevant to the pathogenic mechanisms in asthmatic smokers $[37,94]$.

\section{New approaches for smoking cessation}

Advances in the understanding of the mechanisms involved in nicotine addiction have been recently translated into new medications and vaccines that interfere with nicotine signal- 
ling, many of which are currently in the advanced stage of clinical development and offer promise [88]. These include new pharmaceutical nicotine products, cannabinoid receptor-1 antagonists, dopamine D3 receptor antagonists, and monoamine oxidase inhibitors. Perhaps, the most active areas in smoking cessation pipeline are the development of therapeutic vaccines and the clinical testing of natural nicotinic ligands with partial agonist activity, such as cytisine. Cytisine is a natural alkaloid, which is a structural analogue of nicotine with partial agonistic properties at the $\alpha 4 \beta 2$ nicotinic receptor. Cytisine has been used for smoking cessation in central and eastern European countries for many years [99]. Results from the ongoing controlled clinical trials are eagerly awaited. Nicotine vaccines work by causing the immune system to produce antibodies directed against the nicotine obtained from tobacco smoking, thus reducing the rate and the quantity of nicotine entry into the brain [100]. This reduces the pleasure and other rewarding effects produced by nicotine. Substantial research on this new pharmacological approach is currently ongoing. Positive results from phase II trials have reported that these vaccines are safe and well tolerated, and able to increase the ability of participants to stop smoking [101, 102]. If successful, nicotine vaccines will contribute to the fight against tobacco addiction, probably by preventing relapse.

\section{Restoring corticosteroid sensitivity}

In a series of in vitro studies, low-dose theophylline was shown to restore corticosteroid sensitivity possibly by increasing HDAC2 activity, which is suppressed in smokers. Preliminary data suggests that the addition of low-dose sustained release theophylline restores ICS sensitivity as measured by lung function in smokers with asthma [96]. If larger studies confirm these finding, this treatment combination may be of value in the management of asthmatic smokers. Low-dose theophylline is thought to act, at least in part, through the inhibition of phosphoinositide-3 kinases (PI3K) [103]. Based on encouraging results from pre-clinical studies suggesting that PI3K- $\delta$ inhibitors could potentially reverse corticosteroid insensitivity [104], selective PI3K inhibitors are being developed as novel therapies for the treatment of corticosteroid insensitive airway diseases including smokers with asthma. An alternative approach to restore corticosteroid sensitivity could be through the use of vitamin D, based on studies showing that activation of the vitamin $\mathrm{D}$ receptor may have an immunomodulatory role in asthma [105, 106]. Peripheral blood CD4+ T-cells from patients with corticosteroid resistant asthma recover their sensitivity to corticosteroids following a short course of oral vitamin D [106] and clinical studies are indicated to assess the efficacy of this approach in smokers with asthma. A pilot study is underway to investigate whether inhaled extra-fine beclomethasone may overcome corticosteroid insensitivity in smokers with asthma that may result from impaired peripheral deposition of normal particle size inhaled corticosteroids [80], due to more severe small airway disease in smokers (www.clinicaltrials.gov; NCT01620099).

\section{Anti-inflammatory therapies}

Peroxisome proliferator-activated receptor (PPAR)- $\gamma$ agonists exert anti-inflammatory effects on multiple inflammatory cells including neutrophils and eosinophils [107]. A pilot study using the PPAR- $\gamma$ agonist rosiglitazone, demonstrated bronchodilator effects in mild-to-moderate smokers with asthma [108]. The adverse-effect profile of oral rosiglitazone may preclude its development for asthma, but clinical trials of the oral PPAR- $\gamma$ agonist pioglitazone in severe asthma are underway. Statins have anti-inflammatory effects potentially relevant to the treatment of asthma [109]. Interestingly, asthma quality of life scores improve in smokers with asthma after short-term treatment with atorvastatin [110], although statin treatment fail to show efficacy in nonsmokers with mild-tomoderate asthma [111]. The immunomodulating properties of macrolides, including anti-inflammatory effects on neutrophils and their potential to restore corticosteroid sensitivity would suggest that they may benefit asthmatic smokers. However, 12 weeks of treatment with azithromycin, when added to ICS, does not improve lung function or current asthma control in smokers with asthma [112].

\section{Anti-oxidants}

Cigarette smoke contains huge numbers of oxidative compounds that can contribute to airway inflammation and corticosteroid insensitivity in asthma. To date no studies of anti-oxidants have been performed in smokers with asthma partly due to the lack of suitable anti-oxidant agents that have shown consistent benefit in other smoking-related airway diseases such as COPD [113]. Nevertheless, in the future, potent anti-oxidants may have a role in the treatment of asthmatic smokers.

\section{CONCLUSIONS AND FUTURE DIRECTIONS}

The interaction between smoking and asthma poses multiple challenges for the investigator, the clinician and the patient. The asthmatic smoker may represent a distinct "phenotype" with definite immuno-cellular changes, as well as impaired pharmacologic effects and poor behavioural response to smoking cessation management. Innate immune dysregulation from smoking in the asthmatic has recently been described, but why this occurs and how it can be modulated is not clear. The mechanisms of corticosteroid insensitivity in smokers with asthma are also poorly understood. Given that not all smokers with asthma are insensitive to ICS, searching key phenotypic predictors for this insensitivity may be an important area for future investigation. The increased recognition that active smoking and asthma is indeed a dangerous liaison should result in greater efforts to develop and encourage safe and effective smoking cessation programmes and avoidance strategies. The high prevalence rates of cigarette smoking in asthma, particularly in the developing world, the poor level of asthma control experienced by these patients despite current therapies and the low rates of smoking cessation all highlight the need for improved therapies for smokers with asthma. It is important that future randomised controlled trials of new therapies being developed for asthma recruit current and former smokers with asthma, including those with a heavy-intensity smoking history, to allow suitably powered pre-planned subgroup analysis. Drug licensing agencies should provide support for this position by requesting suitable studies in smokers with asthma prior to licensing new treatments for asthma.

\section{SUPPORT STATEMENT}

R. Polosa's research on smoking and asthma is currently supported by LIAF (Lega Italiana AntiFumo; Catania, Italy). 


\section{STATEMENT OF INTEREST}

Statements of interest for R. Polosa and N.C. Thomson can be found at www.erj.ersjournals.com/site/misc/statements.xhtml

\section{REFERENCES}

1 World Health Organization report on the global tobacco epidemic, 2008. The MPOWER package. Geneva, World Health Organization, 2008. www.who.int/tobacco/mpower/2008/en/ index.html Date last accessed: April 2012.

2 Rabe KF, Adachi M, Lai CKW, et al. Worldwide severity and control of asthma in children and adults: the global asthma insights and reality surveys. J Allergy Clin Immunol 2004; 114: 40-47.

3 Vozoris NT, Stanbrook MB. Smoking prevalence, behaviours, and cessation among individuals with COPD or asthma. Respir Med 2011; 105: 477-484.

4 Cerveri I, Cazzoletti L, Corsico A, et al. The impact of cigarette smoking on asthma: a population-based international cohort study. Int Arch Allergy Immunol 2012; 158: 175-183.

5 To T, Stanojevic S, Moores G, et al. Global asthma prevalence in adults: findings from the cross-sectional world health survey. BMC Public Health 2012; 12: 204.

6 Kiviloog J, Irnell L, Eklund G. The prevalence of bronchial asthma and chronic bronchitis in smokers and non-smokers in a representative local Swedish population. Scand J Respir Dis 1974; 55: 262-276.

7 Chen Y, Dales R, Krewski D, et al. Increased effects of smoking and obesity on asthma among female Canadians: the National Population Health Survey, 1994-1995. Am J Epidemiol 1999; 150: 255-262.

8 Langhammer A, Johnsen R, Holmen J, et al. Cigarette smoking gives more respiratory symptoms among women than among men: the Nord-Trondelag Health Study (HUNT). J Epidemiol Community Health 2000; 54: 917-922.

9 Annesi-Maesano I, Oryszczyn MP, Raherison C, et al. Increased prevalence of asthma and allied diseases among active adolescent tobacco smokers after controlling for passive smoke exposure: a cause for concern? Clin Exp Allergy 2004; 34: 1017-1023.

10 Flodin U, Jonsson P, Ziegler J, et al. An epidemiologic study of bronchial asthma and smoking. Epidemiology 1995; 6: 503-505.

11 Toren K, Hermansson BA. Incidence rate of adult-onset asthma in relation to age, sex, atopy, and smoking: a Swedish population-based study of 15,813 adults. Int J Tuberc Lung Dis 1999; 3: 192-197.

12 Plaschke PP, Janson C, Norrman E, et al. Onset and remission of allergic rhinitis and asthma and the relationship with atopic sensitization and smoking. Am J Respir Crit Care Med 2000; 162: 920-924.

13 Chen $Y$, Dales R, Tang M, et al. Sex-related interactive effect of smoking and household pets on asthma incidence. Eur Respir J 2002; 20: 1162-1166.

14 Piipari R, Jaakkola JJK, Jaakkola N, et al. Smoking and asthma in adults. Eur Respir J 2004; 24: 734-739.

15 Polosa R, Knoke JD, Russo C, et al. Cigarette smoking is associated with a greater risk of incident asthma in allergic rhinitis. J Allergy Clin Immunol 2008; 121: 1428-1434.

16 Thomson NC, Chaudhuri R. Asthma in smokers: challenges and opportunities. Curr Opin Pulm Med 2009; 15: 39-45.

17 Siroux V, Pin I, Oryszcyn MP, et al. Relationships of active smoking to asthma and asthma severity in the EGEA study. Eur Respir J 2000; 15: 470-477.

18 Austin JB, Selvaraj S, Godden D, et al. Deprivation, smoking, and quality of life in asthma. Arch. Dis Child 2005; 90: 253-257.

19 Eisner MD, Iribarren C. The influence of cigarette smoking on adult asthma outcomes. Nicotine Tob Res 2007; 9: 53-56.
20 Shavit O, Swern A, Dong Q, et al. Impact of smoking on asthma symptoms, healthcare resource use, and quality of life outcomes in adults with persistent asthma. Qual Life Res 2007; 16: 1555-1565.

21 Patel SN, Tsai CL, Boudreaux ED, et al. Multicenter study of cigarette smoking among patients presenting to the emergency department with acute asthma. Ann Allergy Asthma Immunol 2009; 103: 121-127.

22 Mitchell I, Tough SC, Semple LK, et al. Near-fatal asthma: a population-based study of risk factors. Chest 2002; 121: 1407-1413.

23 Ulrik CS, Frederiksen J. Mortality and markers of risk of asthma death among 1075 outpatients with asthma. Chest 1995; 108: 10-15.

24 Polosa R, Russo C, Caponnetto P, et al. Greater severity of new onset asthma in allergic subjects who smoke: a 10-year longitudinal study. Respir Res 2011; 12: 16.

25 Chaudhuri R, McSharry C, McCoard A, et al. Role of symptoms and lung function in determining asthma control in smokers with asthma. Allergy 2008; 63: 132-135.

26 Leuppi JD, Steurer-Stey C, Wildhaber J, et al. Asthma control in Switzerland: a general practitioner based survey. Curr Med Res Opin 2006; 22: 2159-2166.

27 Clatworthy J, Price D, Ryan D, et al. The value of self-report assessment of adherence, rhinitis and smoking in relation to asthma control. Prim Care Respir J 2009; 18: 300-305.

28 Laforest L, Van Ganse E, Devouassoux G, et al. Influence of patients' characteristics and disease management on asthma control. J Allergy Clin Immunol 2006; 117: 1404-1410.

29 Schatz M, Zeiger RS, Vollmer WM, et al. Determinants of future longterm asthma control. J Allergy Clin Immunol 2006; 118: 1048-1053.

30 Lange P, Parner J, Vestbo J, et al. A 15-year follow-up study of ventilatory function in adults with asthma. N Engl J Med 1998; 339: 1194-1200.

31 Thomson NC, Spears M. The role of cigarette smoking on persistent airflow obstruction in asthma. Ann Respir Med 2011; 2: 47-54.

32 Jang AS, Park JS, Lee JH, et al. The impact of smoking on clinical and therapeutic effects in asthmatics. J Korean Med Sci 2009; 24 209-214.

33 Apostol G, Jacobs D, Tsai A, et al. Early life factors contribute to the decrease in lung function between ages 18 and 40. Am J Respir Crit Care Med 2002; 166: 166-172.

34 James AL, Palmer LJ, Kicic E, et al. Decline in lung function in the Busselton health study: the effects of asthma and cigarette smoking. Am J Respir Crit Care Med 2005; 171: 109-114.

35 Ulrik CS, Backer V, Dirksen A. A 10 year follow up of 180 adults with bronchial asthma: factors important for the decline in lung function. Thorax 1992; 47: 14-18.

36 Grol MH, Gerritsen J, Vonk JM, et al. Risk factors for growth and decline of lung function in asthmatic individuals up to age 42 years. Am J Respir Crit Care Med 1999; 160: 1830-1837.

37 Spears M, Cameron E, Chaudhuri R, et al. Challenges of treating asthma in people who smoke. Expert Rev Clin Immunol 2010; 6: 257-268.

38 Chalmers GW, Macleod KJ, Little SA, et al. Influence of cigarette smoking on inhaled corticosteroid treatment in mild asthma. Thorax 2002; 57: 226-230.

39 Lazarus SC, Chinchilli VM, Rollings NJ, et al. Smoking affects response to inhaled corticosteroids or leukotriene receptor antagonists in asthma. Am J Respir Crit Care Med 2007; 175: 783-790.

40 Tomlinson JE, McMahon AD, Chaudhuri R, et al. Efficacy of low and high dose inhaled corticosteroid in smokers versus nonsmokers with mild asthma. Thorax 2005; 60: 282-287.

41 Pedersen B, Dahl R, Karlstrom R, et al. Eosinophil and neutrophil activity in asthma in a one-year trial with inhaled budesonide. The impact of smoking. Am J Respir Crit Care Med 1996; 153: 1519-1529. 
42 Pedersen SE, Bateman ED, Bousquet J, et al. Determinants of response to fluticasone propionate and salmeterol/fluticasone propionate combination in the Gaining Optimal Asthma controL study. J Allergy Clin Immunol 2007; 120: 1036-1042.

43 Chaudhuri R, Livingston $\mathrm{E}$, McMahon $\mathrm{AD}$, et al. Cigarette smoking impairs the therapeutic response to oral corticosteroids in chronic asthma. Am J Respir Crit Care Med 2003; 168: 1308-1311.

44 Strachan D, Cook D. Parental smoking and childhood asthma: longitudinal and case-control studies. Thorax 1998; 53: 204-212.

45 US Department of Health and Human Services. The Health Consequences of Involuntary Exposure to Tobacco Smoke: A Report of the Surgeon General. Atlanta, Centers for Disease Control and Prevention, National Centre for Chronic Disease Prevention, 2006.

46 Burke H, Leonardi-Bee J, Hashim A, et al. Prenatal and passive smoke exposure and incidence of asthma and wheeze: systematic review and meta-analysis. Pediatrics 2012; 129: 735-744.

47 Accordini S, Janson C, Svanes C, et al. The role of smoking in allergy and asthma: lessons from the ECRHS. Curr Allergy Asthma Rep 2012; 12: 185-191.

48 Skorge T, Eagan T, Eide G, et al. The adult incidence of asthma and respiratory symptoms by passive smoking in utero or in childhood. Am J Respir Crit Care Med 2005; 172: 61-66.

49 Murphy VE, Clifton VL, Gibson PG. The effect of cigarette smoking on asthma control during exacerbations in pregnant women. Thorax 2010; 65: 739-744.

50 Newman RB, Momirova V, Dombrowski MP, et al. The effect of active and passive household cigarette smoke exposure on pregnant women with asthma. Chest 2010; 137: 601-608.

51 Global strategy for asthma management and prevention. Global Initiative for Asthma (GINA) 2011. www.ginasthma.org Date last accessed: April 2012.

52 Bateman ED, Hurd SS, Barnes PJ, et al. Global strategy for asthma management and prevention: GINA executive summary. Eur Respir J 2008; 31: 143-178.

53 Reddel HK, Taylor DR, Bateman ED, et al. An official American Thoracic Society/European Respiratory Society statement: asthma control and exacerbations: standardizing endpoints for clinical asthma trials and clinical practice. Am I Respir Crit Care Med 2009; 180: 59-99.

54 Comhair SAA, Gaston BM, Ricci KS, et al. Detrimental effects of environmental tobacco smoke in relation to asthma severity. PLoS One 2011; 6: e18574.

55 Menzies D, Nair A, Williamson P, et al. Respiratory symptoms, pulmonary function, and markers of inflammation among bar workers before and after a legislative ban on smoking in public places. JAMA 2006; 296: 1742-1748.

56 Higenbottam T, Feyeraband C, Clark T. Cigarette smoking in asthma. Br J Dis Chest 1980; 74: 279-284.

57 Jensen E, Dahl R, Steffensen F. Bronchial reactivity to cigarette smoke; relation to lung function, respiratory symptoms, serumimmunoglobulin E and blood eosinophil and leukocyte counts. Resp Med 2000; 94: 119-127.

58 Vestbo J, Edwards LD, Scanlon PD, et al. Changes in forced expiratory volume in 1 second over time in COPD. N Engl J Med 2011; 365: 1184-1192.

59 Chaudhuri R, Livingston E, McMahaon AD, et al. Effects of smoking cessation on lung function and airway inflammation in smokers with asthma. Am J Respir Crit Care Med 2006; 174 127-133.

60 Dijkstra A, Vonk JM, Jongepier $\mathrm{H}$, et al. Lung function decline in asthma: association with inhaled corticosteroids, smoking and sex. Thorax 2006; 61: 105-110.

61 Lange $\mathrm{P}$, Scharling $\mathrm{H}$ et al. Inhaled corticosteroids and decline of lung function in community residents with asthma. Thorax 2006; 61: $100-104$
62 O'Byrne PM, Lamm CJ, Busse WW, et al. The effects of inhaled budesonide on lung function in smokers and nonsmokers with mild persistent asthma. Chest 2009; 136: 1514-1520.

63 Boulet LP, Lemiere C, Archambault F, et al. Smoking and asthma: clinical and radiologic features, lung function, and airway inflammation. Chest 2006; 129: 661-668.

64 Chalmers GW, Macleod KJ, Thomson L, et al. Smoking and airway inflammation in patients with mild asthma. Chest 2001; 120: 1917-1922.

65 Stanescu D, et al. Airways obstruction, chronic expectoration, and rapid decline of FEV1 in smokers are associated with increased levels of sputum neutrophils. Thorax 1996; 51: 267-271.

66 Broekema M, ten Hacken NH, Volbeda F, et al. Airway epithelial changes in smokers but not in ex-smokers with asthma. Am J Respir Crit Care Med 2009; 180: 1170-1178.

67 Löffek S, Schilling O, Franzke CW. Biological role of matrix metalloproteinases: a critical balance. Eur Respir J 2011; 38: 191-208.

68 Chaudhuri R, McSharry C, Brady J, et al. Sputum MMP-12 in COPD and asthma: relationship to disease severity. J Allergy Clin Immunol 2012; 129: 655-663.

69 Polosa R, Salvi S, Di Maria GU. Allergic susceptibility associated with diesel exhaust particle exposure: clear as mud. Arch Environ Health 2002; 57: 188-193.

70 Diaz-Sanchez D, Rumold R, Gong H Jr. Challenge with environmental tobacco smoke exacerbates allergic airway disease in human beings. J Allergy Clin Immunol 2006; 118: 441-446.

71 Floreani AA, Rennard SI. The role of cigarette smoke in the pathogenesis of asthma and as a trigger for acute symptoms. Curr Opin Pulm Med 1999; 5: 38-46.

72 Piccillo G, Caponnetto P, Barton S, et al. Changes in airway hyperresponsiveness following smoking cessation: comparisons between Mch and AMP. Respir Med 2008; 102: 256-265.

73 Holgate ST, Polosa R. The mechanisms, diagnosis, and management of severe asthma in adults. Lancet 2006; 368: 780-793.

74 Cazzola M, Polosa R. Anti-TNF-alpha and Th1 cytokine-directed therapies for the treatment of asthma. Curr Opin Allergy Clin Immunol 2006; 6: 43-50.

75 Barnes P. Mechanisms and resistance in glucocorticoid control of inflammation. I Steroid Biochem Mol Biol 2010; 120: 76-85.

76 Adenuga D, Yao H, March TH, et al. Histone deacetylase 2 is phosphorylated, ubiquitinated, and degraded by cigarette smoke. Am J Respir Cell Mol Biol 2009; 40: 464-473.

77 Livingston E, Darroch CE, Chaudhuri R, et al. Glucocorticoid receptor alpha:beta ratio in blood mononuclear cells is reduced in cigarette smokers. J Allergy Clin Immunol 2004; 114: 1475-1478.

78 Adams RJ, Weiss ST, Fuhlbrigge A. How and by whom care is delivered influences anti-inflammatory use in asthma: results of a national population survey. J Allergy Clin Immunol 2003; 112: 445-450.

79 Tinkelman DG, Price DB, Nordyke RJ, et al. Misdiagnosis of COPD and asthma in primary care patients 40 years of age and over. I Asthma 2006; 43: 75-80.

80 Invernizzi G, Ruprecht A, De Marco C, et al. Inhaled steroid/ tobacco smoke particle interactions: a new light on steroid resistance. Resp Res 2009; 10: 48

81 Venarske DL, Busse WW, Griffin MR, et al. The relationship of rhinovirus-associated asthma hospitalizations with inhaled corticosteroids and smoking. J Infect Dis 2006; 193: 1536-1543.

82 Svanes $C$. What has the ECRHS told us about the childhood risk of asthma, allergy and lung function? Clin Respir J 2008; 2: Suppl. $1,34-44$.

83 Tonnesen P, Pisinger C, Hvidberg S, et al. Effects of smoking cessation and reduction in asthmatics. Nicotine Tob Res 2005; 7 : 139-148.

84 Fennerty AG, Banks I, Ebden P, et al. The effect of cigarette withdrawal on asthmatics who smoke. Eur J Respir Dis 1987; 71: 395-399. 
85 Eisner MD, Yelin EH, Katz PP, et al. Predictors of cigarette smoking and smoking cessation among adults with asthma. Am J Public Health 2000; 90: 1307-1311.

86 Wakefield M, Ruffin R, Campbell D, et al. Smoking-related beliefs and behaviour among adults with asthma in a representative population sample. Aust NZ J Med 1995; 25: 12-17.

87 Fiore MC, Jaen CR, Baker TB, et al. Clinical practice guidelines: Treating tobacco use and dependence: 2008 update. US Dept of Health and Human Services, Public Health Service, 2008. www. ahrq.gov/clinic/tobacco/treating_tobacco_use08.pdf Date last accessed: April 2012.

88 Polosa R, Benowitz NL. Treatment of nicotine addiction: present therapeutic options and pipeline developments. Trends Pharmacol Sci 2011; 32: 281-289.

89 Caponnetto P, Polosa R. Common predictors of smoking cessation in clinical practice. Respir Med 2008; 102: 1182-1192.

90 Cummings KM, Giovino G, Jaen CR, et al. Reports of smoking withdrawal symptoms over a 21-day period of abstinence. Addict Behav 1985; 10: 373-381.

91 Caponnetto P, Polosa R, Best D. Tobacco use cessation counseling of parents. Curr Opin Pediatr 2008; 20: 729-733.

92 World Health Organization report on the global tobacco epidemic, 2009; implementing smoke-free environments. Geneva, World Health Organization, 2009. www.who.int/tobacco/mpower/ 2009/gtcr_download/en/index.html Date last accessed: April 2012.

93 World Health Organization. The European Tobacco Control Report 2007. Geneva, World Health Organization, 2007. www. euro.who.int/_data/assets/pdf_file/0005/68117/E89842.pdf Date last accessed: April 2012

94 Thomson NC, Spears M. Asthma guidelines and smoking: it's time to be inclusive. Chest 2012; 141: 286-288.

95 Clearie K, McKinlay L, Williamson $\mathrm{P}$, et al. Fluticasone/ salmeterol combination confers benefits in smoking asthmatics. Chest 2012; 141: 330-338.

96 Spears M, Donnelly I, Jolly L, et al. Effect of low-dose theophylline plus beclometasone on lung function in smokers with asthma: a pilot study. Eur Respir J 2009; 33: 1010-1017.

97 Magnussen H, Bugnas B, van Noord J, et al. Improvements with tiotropium in COPD patients with concomitant asthma. Resp Med 2008; 102: 50-56.

98 van Schayck OCP, Haughney J, Aubier M, et al. Do asthmatic smokers benefit as much as non-smokers on budesonide/ formoterol maintenance and reliever therapy? Results of an open label study. Respir Med 2012; 106: 189-196.

99 Etter JF, Lukas RJ, Benowitz NL, et al. Cytisine for smoking cessation: a research. Drug Alcohol Depend 2008; 92: 3-8.
100 Maurer P, Bachmann MF. Vaccination against nicotine: an emerging therapy for tobacco dependence. Expert Opin Investig Drugs 2007; 16: 1775-1783.

101 Xenova Group PLC. News release. Anti-smoking vaccine TANIC preliminary 12 month clinical trial. March 2005. http:// hugin.info/133161/R/982993/146255.pdf Date last accessed: April 2012.

102 Hatsukami DK, Rennard S, Jorenby D, et al. Safety and immunogenicity of a nicotine conjugate vaccine in current smokers. Clin Pharmacol Ther 2005; 78: 456-467.

103 Ito K, Caramori G, Adcock IM. Therapeutic potential of phosphatidylinositol 3-kinase inhibitors in inflammatory respiratory disease. J Pharmacol Exp Ther 2007; 321: 1-8.

104 Marwick JA, Caramori G, Stevenson CS, et al. Inhibition of pi3k $\delta$ restores glucocorticoid function in smoking-induced airway inflammation in mice. Am J Respir Cri Care Med 2009; 179: 542-548.

105 Brehm JM, Celedon JC, Soto-Quiros ME, et al. Serum vitamin D levels and markers of severity of childhood asthma in costa rica Am J Respir Crit Care Med 2009; 179: 765-771.

106 Xystrakis E, Kusumakar S, Boswell S, et al. Reversing the defective induction of IL-10-secreting regulatory $\mathrm{T}$ cells in glucocorticoid-resistant asthma patients. J Clin Invest 2006; 116: 146-155

107 Spears M, McSharry C, Thomson NC. Peroxisome proliferatoractivated receptor-gamma agonists as potential anti-inflammatory agents in asthma and chronic obstructive pulmonary disease. Clin Exp Allergy 2006; 36: 1494-1504.

108 Spears M, Donnelly I, Jolly L, et al. Bronchodilatory effect of the PPAR $-\gamma$ agonist rosiglitazone in smokers with asthma. Clin Pharmacol Ther 2009; 86: 49-53.

109 Hothersall E, McSharry C, Thomson NC. Potential therapeutic role for statins in respiratory disease. Thorax 2006; 61: 729-734.

110 Braganza G, Chaudhuri R, McSharry C, et al. Effects of shortterm treatment with atorvastatin in smokers with asthma - a randomized controlled trial. BMC Pulm Med 2011; 11: 16.

111 Hothersall EJ, Chaudhuri R, McSharry C, et al. Effects of atorvastatin added to inhaled corticosteroids on lung function and sputum cell counts in atopic asthma. Thorax 2008; 63: 1070-1075.

112 Cameron EJ, Chaudhuri R, McSharry C, et al. Effects of azithromycin on asthma control, airway inflammation and bacterial colonization in smokers with asthma - a randomized controlled trial. Am J Respir Crit Care Med 2012; 185: A3965.

113 Zheng J-P, Kang J, Huang S-G, et al. Effect of carbocisteine on acute exacerbation of chronic obstructive pulmonary disease (PEACE study): a randomised placebo-controlled study. Lancet 2008; 371: 2013-2018. 